ORI GI NAL

\title{
I DENTI FICACIÓN PRELIMINAR IN VITRO DE PROPIEDADES PROBIÓTICAS EN CEPAS DE S. cerevisiae
}

\section{N VI TRO PRELI MI NARY I DENTI FI CATI ON OF PROBI OTI C PROPERTIES OF S. cerevisiae STRAINS}

\author{
Ana Rubio M, Microbiol, María Hernández E, Microbiol, Andréa Aguirre R, ${ }^{*}$ M.Sc, \\ Raúl Poutou P, Ph.D.
}

Pontificia Universidad Javeriana. Facultad de Ciencias. Departamento de Microbiología. Grupo de Biotecnología Ambiental e Industrial, Lab. de Biotecnología Aplicada. Bogotá, Colombia. *Correspondencia: aaguirr@javeriana.edu.co

\author{
Recibido: Octubre 16 de 2007; Aceptado: Enero 10 de 2008
}

\section{RESUMEN}

Objetivo. Evaluar preliminarmente in vitro algunas propiedades probióticas de dos cepas nativas de S. cerevisiae. Materiales y métodos. Las cepas fueron utilizadas en ensayos de tolerancia a sales biliares, pH, temperatura, adherencia a Salmonella spp., E. coli y Shigella spp., y antagonismo. Se realizó un diseño factorial $3^{3} \times 3$, con tres niveles de cada factor (cepa, pH y concentración inicial de sustrato) por triplicado, para establecer las condiciones de cultivo de cada cepa. Como control se empleó una cepa comercial (B). La cepa seleccionada se empleó para la producción en biorreactor de 2L; la biomasa fue sometida a secado por temperatura; al producto resultante se le determinó concentración de $\mathrm{N}_{2}$ y la viabilidad celular. Resultados. La cepa A (obtenida de caña de azúcar), toleró $\mathrm{pH} 3 \pm 0.2,0.3 \%$ (p/v) de sales biliares y $42^{\circ} \mathrm{C}$. El ANOVA del diseño factorial reportó diferencias significativas entre los 27 ensayos ( $p \leq 0.05)$, el análisis de superficies reportó que la interacción entre los factores cepa y Sustrato $\left(S_{0}\right)$ son significativos, sugiriendo para la optimización la cepa A y concentraciones crecientes de $S_{0}$. Los resultados se reprodujeron en biorreactor con $\mathrm{m}_{\mathrm{x}} 0.31 \mathrm{~h}^{-1}$, td $2.18 \mathrm{~h}$ y $\mathrm{Y}_{(\mathrm{x} / \mathrm{s})} 0.126 \mathrm{~g} / \mathrm{g}$; la biomasa seca obtenida fue viable y reportó entre 6.3 y $6.9 \% \mathrm{~N}_{2} / \mathrm{g}$. Conclusiones. Se identificaron levaduras nativas con propiedades probióticas como tolerancia a pH, sales biliares, temperatura y adherencia a Salmonella spp., E.coli y Shigella spp.

Palabras clave: Saccharomyces cerevisiae, probióticos, superficie de respuesta. 


\section{ABSTRACT}

Objective. To evaluate probiotic properties of two native strains of $\mathrm{S}$. cerevisiae. Materials and methods. Strains were used in assays for tolerance to biliary salts, $\mathrm{pH}$, temperature and adhesion to Salmonella spp., E. coli and Shigella spp. and antagonism. A $3^{3} \times 3$ factorial design was used, with three levels for each factor (strains, $\mathrm{pH}$ and initial concentration of substrate (S )) by triplicate, to establish the culture conditions for each strain. A commercial strain (B) was used as control. The selected strain was cultured in a $2 \mathrm{~L}$ bioreactor; the biomass was dryed by temperature and the resulting product was assayed to determine $\mathrm{N}$ concentration and cellular viability. Results. Strain A (from sugar cane), tolerated $\mathrm{pH} 3 \pm^{2}$ $0.2,0.3 \%(\mathrm{w} / \mathrm{v})$ of biliary salts and $42^{\circ} \mathrm{C}$. The factorial ANOVA found significant differences between the 27 assays $(p<0.05)$ and surface analysis found that the interaction between factors strain and $S$ was significant, suggesting for the optimization process the use of strain $A$ and increasing concentrations of $S$. Results were reproduced in bioreactor with $m_{X}$ $0.31 \mathrm{~h}^{-1}$, dt $2.18 \mathrm{~h}$ and $Y_{(x / s)} 0.126 \mathrm{~g} / \mathrm{g}$. the dry biomass obtained was viable and yielded between 6.3 and $6.9 \% \mathrm{~N}_{2} / \mathrm{g}$. Conclusions. Native strains were identified with probiotic properties such as $\mathrm{pH}$, biliary salt and temperature tolerance, and adherence to Salmonella spp., E .coli and Shigella spp.

Key words: Saccharomyces cerevisiae, probiotic, answer surface.

\section{NTRODUCCIÓN}

Desde la antigüedad los microorganismos se han utilizado para producir alimentos, de esta manera han formado parte integral de la dieta del hombre y de los animales, probablemente los primeros alimentos que contenían microorganismos fueron las leches fermentadas cuyo consumo permanece actualmente. La verdadera importancia de los microorganismos fue comprendida a comienzos del siglo pasado. Levaduras como S. cerevisiae y Pichia pastoris han sido empleadas para la producción de proteína unicelular (SCP) por ser reconocidas como seguras (GRAS), por poseer una alta velocidad de multiplicación, por ser capaces de emplear un gran variedad de fuente de carbono, por no producir compuestos tóxicos, por presentar un contenido de proteína cruda entre 55 y $60 \%$ del peso seco; lo que ha permitido que sean aceptadas como alimentos o piensos $(1,2)$.

A nivel mundial la producción de biomasa a partir de levaduras se ha incrementado con diversos fines, entre ellos la fabricación de preparados probióticos. La palabra probiótico significa "para la vida", estos biopreparados son confeccionados a base de cultivos microbianos cuya función es estimular la flora gastrointestinal en animales y humanos.
Algunos de los efectos probióticos reportados son la producción de enzimas, vitaminas y aminoácidos, la adherencia a microvellosidades intestinales y por exclusión competitiva desplazan a los microorganismos patógenos. El efecto antagónico sobre los mismos, la regulación del $\mathrm{pH}$ y disminución del potencial redox, la producción de bacteriocinas, el aumento en la asimilación de los alimentos, la reducción de los niveles de colesterol, la estimulación del sistema inmune y la aceleración del reinicio de la actividad ovárica post-parto en vacas, entre otros (3-5).

Para la producción de SCP a partir de levaduras, se han estudiado cepas de S. cerevisiae subespecie boulardii, demostrando que estas producen beneficios en el tracto gastrointestinal de los animales monogástricos, impidiendo la adherencia de bacterias patógenas al tracto digestivo, inhibiendo las toxinas bacterianas y promoviendo condiciones favorables para el crecimiento y producción de bacterias ácidolácticas (2).

En animales monogástricos los probióticos a base de levaduras han sido suministrados simultáneamente durante la administración 
de antibióticos, durante cambios de formulación en las dietas, durante procesos diarreicos y en general, en todos aquellos procesos que promuevan la disminución de la microflora intestinal; lo cual ha sido reevaluado cuando se emplean bacterias ácido lácticas (BAL).

En Colombia el uso de este tipo de biopreparados a partir de cepas nativas de levaduras puede ser una alternativa válida, ya que disminuiría la producción a gran escala menos dependiente de productos importados que generan mayor inversión. El objetivo de este trabajo fue evaluar preliminarmente "in vitro" algunas propiedades probióticas de dos cepas nativas de levaduras.

\section{MATERI ALES Y MÉTODOS}

Sitio y lugar de estudio. El trabajo fue desarrollado en el Laboratorio de Biotecnología Aplicada, Grupo de Biotecnología Ambiental e Industrial, Departamento de Microbiología, Facultad de Ciencias, de la Pontificia Universidad Javeriana. Bogotá, Colombia.

Conservación de cepas. Se utilizaron tres cepas de S. cerevisiae., aisladas y recuperadas a partir de diferentes fuentes; la cepa A fue obtenida de caña de azúcar, la cepa B (cepa control) a partir de un producto probiótico comercial y la cepa C aislada de Vid. Todas las cepas fueron conservadas en Banco de Células Primario (BCP) en caldo YPG (Extracto de levadura $1 \%(p / v)$, Peptona 2\% (p/v), Glicerol 30\% $(p / v)) a-70 \circ C(6)$.

Tolerancia a sales biliares, pH y temperatura. La capacidad probiótica de las levaduras se evaluó a través de pruebas de tolerancia a $\mathrm{pH}(3,4,5,6$ y $7 \pm 0.2)$, y sales biliares $(0.05,0.10,0.15$ y $0.30 \%$ $(p / v))$, empleando el método ecométrico modificado (7). El índice de crecimiento absoluto (ICA) se determinó sobre agar YPD tomando como control cada cepa sembrada en medio YPD sin sales biliares y $\mathrm{pH}$ $7.0 \pm 0.2$ las cuales deberían reportar ICA superior a 4.0. La tolerancia a la temperatura se midió empleando el método ecométrico modificado y las temperaturas evaluadas fueron 28,37 y $43^{\circ} \mathrm{C} \pm 1$. Todos los ensayos se realizaron por triplicado y se incubaron a $30^{\circ} \mathrm{C}$ excepto para la tolerancia a temperatura, durante $24 \mathrm{~h}$ (8).

Prueba preliminar de inhibición de la adherencia de patógenos. La prueba se realizó sembrando cada cepa en agar YPD, a $30 \circ \mathrm{C} 200$ r.p.m., durante 24 h, posteriormente se realizaron sub-cultivos en $10 \mathrm{ml}$ de tampón fosfato PBS, suplementado con glutaraldehido $1 \mathrm{mg} / \mathrm{ml}$ y se incubó $1 \mathrm{~h}$ a $28^{\circ} \mathrm{C}$. Pasada la hora se lavó 3 veces la biomasa con PBS, se centrifugó $10 \mathrm{~min}$ a $5000 \mathrm{~g}$, el precipitado fue resuspendido en $5 \mathrm{ml}$ de PBS suplementado con glicina 10 $\mathrm{mg} / \mathrm{ml}$ y se incubó $30 \mathrm{~min}$ a 28 o C, se centrífugo por $10 \mathrm{~min}$ a $1000 \mathrm{~g}$; el precipitado fue resuspendido en $3 \mathrm{ml}$ de PBS suplementado con $\mathrm{NaN}_{3} 0.02 \%(p / v)$ y se conservó a $4^{\circ} \mathrm{C}$.

Las suspensiones de los patógenos E. coli, Salmonella spp., y Shigella spp., se prepararon en caldo $\mathrm{BHI}$ a concentración $15 \times 10^{8}$ células $/ \mathrm{ml}$. La concentración de las levaduras obtenidas en el paso anterior fue ajustada a $3 \times 10^{8}$ células $/ \mathrm{ml}$. Posteriormente se mezclaron $20 \mathrm{ml}$ de cada patógeno, $20 \mathrm{ml}$ de cada levadura y $10 \mathrm{ml}$ de PBS; las mezclas que fueron incubadas a $37^{\circ} \mathrm{C}$. La reacción de adherencia fue seguida entre 1 y $10 \mathrm{~h}$ y el número de bacterias adheridas a la levadura fue estimado microscópicamente empleando coloración de Gram. Para este cálculo se contaron 20 levaduras en cada observación (9).

Pruebas de antagonismo. Se preparó una emulsión ( $10^{8} \mathrm{UFC} / \mathrm{ml}$ ) a partir de cada cepa de levadura en caldo YPD, las muestras fueron incubadas a $30^{\circ} \mathrm{C}, 200$ r.p.m durante $24 \mathrm{~h}$. Se centrifugaron a 5000 g., y 4으, resuspendiendo el "pellet" en $0.5 \mathrm{ml}$ de agua peptonada al $0.1 \%(p / v)$ (9). Salmonella spp., Escherichia coli y Shigella spp., fueron cultivadas en caldo $\mathrm{BHI}$ a $370 \mathrm{C}$, durante 12 h a 200 r.p.m. A partir de estos cultivos se realizaron siembras masivas sobre agar Mueller Hinton. Para la prueba de antagonismo una vez sembrados en superficie los patógenos, se perforaron pozos de $5 \mathrm{~mm}$ de diámetro en el agar, en los cuales 
se adicionaron $10 \mathrm{ml}$ de la suspensión de células de cada una de las levaduras. Las cajas fueron incubadas a 37 으 entre 24 48 horas. Posteriormente se midieron los halos de inhibición del crecimiento, como control negativo se utilizó agua peptonada al $0.1 \%(\mathrm{p} / \mathrm{v})$ y como control positivo se emplearon sensidiscos de penicilina 100 $\mathrm{mg} / \mathrm{ml}$. El ensayo se realizó por triplicado para cada una de las cepas (9). De la misma manera las levaduras $A$ y $C$ fueron enfrentadas entre ellas.

\section{Curvas de crecimiento en erlenmeyer} agitado y análisis estadístico. Para el estudio cinético de crecimiento se realizó un diseño factorial $3^{3} \times 3$, en el cual se emplearon 3 factores (cepa, $\mathrm{pH}$ y concentración de glucosa inicial teórica) y tres niveles de cada una de los factores, cepas $(A, B$ y $C), p H$ inicial $(7.0 \pm 0.2$, $6.0 \pm 0.2$ y $5.0 \pm 0.2$ ) y concentraciones de glucosa inicial teórica $(10 \mathrm{~g} / \mathrm{l}, 20 \mathrm{~g} / \mathrm{l}$ y $30 \mathrm{~g} / \mathrm{l}$ ) por triplicado; de está manera se definieron 27 tratamientos (Tabla 1). Para el diseño de los experimentos se empleó el programa Desig-Expert 6.0.6- 2002.

La variable dependiente considerada para ver el efecto de los tratamientos fue la concentración de biomasa seca en g/l la cual fue medida durante $20 \mathrm{~h}$ a intervalos de $2 \mathrm{~h}$. La densidad óptica $\mathrm{DO}_{620 \mathrm{~nm}}$ fue transformada a peso seco según la ecuación 1 y la concentración de glucosa residual fue medida cada 2 h. Para la determinación de azúcares reductores se empleó la técnica del ácido 3-5 dinitrosalicílico (DNS) descrita por Miller (10); los $\mathrm{g} / \mathrm{L}$ de glucosa fueron obtenidos a través de la ecuación 2 .

Con estos datos se calculó el rendimiento biomasa/sustrato, $\left.Y_{(x / s)}\right)(g / g)$. En todos los análisis las réplicas fueron manejadas independientemente. Los cultivos fueron realizados en erlenmeyer agitado de $500 \mathrm{ml}$ con $100 \mathrm{ml}$ de medio. El inóculo fue cultivado en YPD y crecido toda la noche a $30^{\circ} \mathrm{C}$, 200 r.p.m. Para el análisis estadístico y para determinar la velocidad específica de crecimiento $m_{x)}\left(h^{-1}\right)$ y el tiempo de duplicación td $(h)$, los datos de biomasa fueron transformados logarítmicamente según la fórmula 3.

$$
\begin{gathered}
Y=0.6151 \chi+0.1835 \\
Y=0.3604 \chi+0.0122 \\
L N\left(\frac{X}{X_{1 D}}\right)
\end{gathered}
$$

Fórmula 3, donde:

$\mathrm{X}_{0}$ representa la biomasa $(\mathrm{g} / \mathrm{I})$ en la $0 \mathrm{~h}$ del proceso (una vez inoculado)

X representa la biomasa $(\mathrm{g} / \mathrm{l})$ en cada una de las horas del proceso.

Los demás parámetros cinéticos fueron calculados según las fórmulas siguientes:

$$
\begin{aligned}
& \mu_{(v)}=\frac{1}{x} \frac{d x}{d t} \\
& t d=\frac{\operatorname{Ln}(2)}{\mu_{(v)}} \\
& Y_{(\%)}=\frac{d x}{d s}
\end{aligned}
$$

Una vez transformados logarítmicamente se analizó la normalidad de los datos por Shapiro-Wilk y Kolmogorov-Smirnov. Verificada la normalidad, los datos fueron sometidos a un análisis de ANOVA, para el cual se empleó el paquete estadístico SPSS 12.0 y se fijó un nivel de significancia de 0.05 ; las hipótesis planteadas fueron las siguientes:

Ho: $\mu_{1}=\mu_{2}=\mu_{3}=\ldots=\mu_{n}$

Hi: al menos una de las medias es diferente

Si $p>0.05$ se acepta la Ho.

SI $p<0.05$ se rechaza la Ho.

Los datos de $\mu_{(x)}\left(\mathrm{h}^{-1}\right)$ y concentración inicial de glucosa $\left(S_{0}\right)$ fueron introducidos en el paquete estadístico SIMFIT 5.4, (11), para la estimación de la velocidad máxima de crecimiento $\mu_{\text {(max) }}\left(\mathrm{h}^{-1}\right)$ y la constante de afinidad por el sustrato $\mathrm{Ks}(\mathrm{g} / \mathrm{l})$ a partir de las combinaciones de $\mathrm{pH}$ y cepa. 
La superficie de respuesta del diseño factorial fue analizada en Statistica 6.0. Los niveles (bajo, medio y alto) de los factores estudiados fueron introducidos de manera nominal; $X_{1}$ (cepas $C, A$ y $\left.B\right), X_{2}(p H$ inicial $5.0,6.0$ y $7.0 \pm 0.2)$ y $X_{3}\left(S_{0} 10 \mathrm{~g} / \mathrm{l}, 20 \mathrm{~g} / \mathrm{l}\right.$ y $30 \mathrm{~g} / \mathrm{l})$. Como variable de respuesta se empleó la biomasa ( $\mathrm{g} / \mathrm{l}$ ) transformada logarítmicamente según la fórmula 3.

\section{Curvas de crecimiento en biorreactor de}

2l. Las condiciones del pre-inóculo e inóculo fueron las empleadas en los ensayos anteriores. El cultivo se realizó con la cepa que mostró propiedades probióticas superiores o iguales al control (Cepa B) y fue mantenido a $30^{\circ} \mathrm{C}, 150-200$ r.p.m., 2 v.v.m., en caldo YPD $\sim 24 \mathrm{~g} / \mathrm{l}$ de glucosa, el seguimiento se realizó cada 2 h hasta completar las $20 \mathrm{~h}$ de cultivo. Los azúcares reductores totales residuales se midieron por DNS (10) y la $D_{620 n m}$ fue empleada para calcular la concentración de biomasa seca g/l (Fórmula 1). La representación gráfica de los resultados se logró a través del paquete $\Sigma$ SigmaPlot 10.0, 2006.

Secado de la biomasa y determinación del porcentaje de viabilidad. La biomasa obtenida en el biorreactor fue lavada tres veces con solución salina $(\mathrm{NaCl} 0.85 \%$ $(\mathrm{p} / \mathrm{v}))$, centrifugada a $5000 \mathrm{~g}$ y resuspendida en solución salina. Para determinar la viabilidad (UFC/g de biomasa) se realizaron recuentos por siembra en superficie en agar YPD a partir de diluciones seriadas de la suspensión de células. Cinco mililitros de la suspensión de levaduras fueron depositados en una caja de petri estéril (previamente pesada). Como control se emplearon $5 \mathrm{ml}$ de solución salina en una caja de petri (previamente pesada); el peso de la biomasa húmeda ( $\mathrm{g}$ ) se determinó por la diferencia de peso (tara) entre la caja de petri con solución salina y la caja de petri con la suspensión de levaduras. Posteriormente se evaluaron dos temperaturas para el secado de la biomasa ( 37 y $42^{\circ} \mathrm{C} \pm 1$ ) con el fin de determinar el tiempo de secado (12).

Después de secar y pesar la biomasa fue resuspendida nuevamente en solución salina sembrada en agar nutritivo para evaluar el efecto de la temperatura de secado sobre la viabilidad celular.
Determinación del contenido $\mathbf{N}_{2}$ de la biomasa obtenida. La determinación de $\mathrm{N}_{2}$ se llevó a cabo mediante el método de Kjeldahl. El contenido de proteína total se determinó midiendo el contenido de nitrógeno amínico según la Norma Técnica Colombiana 1982 (13).

\section{RESULTADOS}

Las cepas A y $\mathrm{C}$ mostraron tolerancia a todas las concentraciones de sales biliares evaluadas. En contraste con la cepa B en la cual disminuyó el ICA (Tabla 1) en todas las concentraciones ensayadas. En las pruebas de tolerancia a $\mathrm{pH}$ se observa que la cepa A, generó valores superiores de ICA en todos los pH evaluados, la cepa $\mathrm{C}$ también muestra alta tolerancia en los rangos de $3.0-7.0 \pm 0.2$, en contraste con la cepa B la cual disminuyó notablemente el ICA en todos los rangos de pH (Tabla 2). Las pruebas de tolerancia a temperatura mostró valores de ICA superiores a 4 para las tres cepas a 28 y $37^{\circ} \mathrm{C} \pm 1$ a diferencia de los resultados encontrados a $42^{\circ} \mathrm{C} \pm 1$, donde el ICA disminuyó de manera considerable para las cepas B y C y ligeramente para la cepa A (Tabla 2, Figura 1).

La prueba de inhibición de la adherencia de los patógenos mostró relaciones máximas (patógeno: levadura) de 20:1 (E.coli: Cepa A) 3 h, 5:1 (E.coli: Cepa B) 3 h, 20:1 (E.coli: Cepa C) 4 h, 18:1 (Salmonella spp.: Cepa

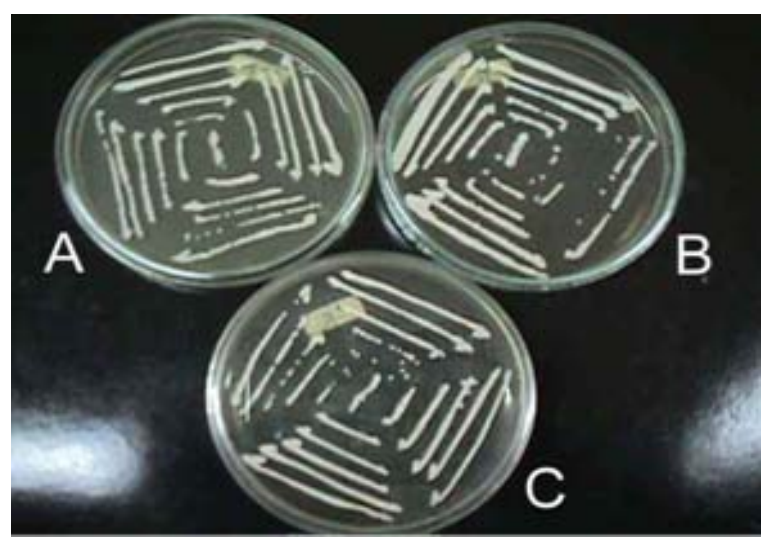

Figura 1. Método ecométrico modificado (9). Prueba de tolerancia a sales biliares. $0.1 \%(\mathrm{p} /$ v) (A). Prueba de tolerancia a $\mathrm{pH} 3.0 \pm 0.2$ (B). Prueba de tolerancia a 28ㄷ (C) Cepa A. Agar YPD. 
Tabla 1. Tratamientos resultantes del diseño factorial $3^{3} \times 3$

\begin{tabular}{|c|c|c|c|}
\hline Tratamiento & Cepa & $\mathrm{pH} \pm 0.2$ & Medio/ Conc. Glucosa \% (p/ v) \\
\hline $\mathrm{T}_{1}$ & A & 7 & YPD/ 1 \\
\hline $\mathrm{T}_{2}$ & & & YPD/2 \\
\hline $\mathrm{T}_{3}$ & & & YPD/3 \\
\hline $\mathrm{T}_{4}$ & & 6 & YPD/ 1 \\
\hline $\mathrm{T}_{5}$ & & & $\mathrm{YPD} / 2$ \\
\hline $\mathrm{T}_{6}$ & & & YPD/3 \\
\hline $\mathrm{T}_{7}$ & & 5 & YPD/ 1 \\
\hline $\mathrm{T}_{8}$ & & & YPD/2 \\
\hline $\mathrm{T}_{9}$ & & & YPD/3 \\
\hline$T_{10}$ & B & 7 & YPD/ 1 \\
\hline $\mathrm{T}_{11}$ & & & YPD/2 \\
\hline$T_{12}$ & & & $\mathrm{YPD} / 3$ \\
\hline $\mathrm{T}_{13}$ & & 6 & YPD/ 1 \\
\hline $\mathrm{T}_{14}$ & & & YPD/2 \\
\hline $\mathrm{T}_{15}$ & & & YPD/3 \\
\hline $\mathrm{T}_{16}$ & & 5 & YPD/ 1 \\
\hline $\mathrm{T}_{17}$ & & & YPD/2 \\
\hline $\mathrm{T}_{18}$ & & & YPD/3 \\
\hline $\mathrm{T}_{19}$ & C & 7 & YPD/ 1 \\
\hline $\mathrm{T}_{20}$ & & & YPD/2 \\
\hline$T_{21}$ & & & YPD/3 \\
\hline$T_{22}$ & & 6 & YPD/ 1 \\
\hline$T_{23}$ & & & YPD/2 \\
\hline $\mathrm{T}_{24}$ & & & YPD/3 \\
\hline $\mathrm{T}_{25}$ & & 5 & YPD/ 1 \\
\hline $\mathrm{T}_{26}$ & & & YPD/2 \\
\hline$T_{27}$ & & & YPD/3 \\
\hline
\end{tabular}

A) 7 h, 7:1 (Salmonella spp.: Cepa B) $3 \mathrm{~h}$, 12:1 (Salmonella spp.: Cepa C) $4 \mathrm{~h}, 15: 1$ (Shigella spp.: Cepa A) 4 h, 20:1 (Shigella spp.: Cepa B) 4 h, 4: 1 (Shigella spp.: Cepa C) $3 \mathrm{~h}$; lo que demostró que las cepas A y C tienen más afinidad por E.coli y Salmonella spp., y que las cepas A y B tienen mayor afinidad por Shigella spp. Las adherencias promedio fueron 18: 1, 11: 1 y 12: 1 para las cepas $A$, B y $C$ respectivamente (Figura 2 ). No se observaron halos de inhibición del crecimiento generados por las cepas en

Tabla 2. Índice de crecimiento absoluto (ICA), como indicador de tolerancia a sales biliares, pH y temperatura.

\begin{tabular}{c|cccc|cccccc|ccc}
\hline \multirow{2}{*}{ Cepas } & \multicolumn{3}{|c|}{ Sales Biliares \% (p/v) } & \multicolumn{7}{c|}{$\mathbf{p H} \pm \mathbf{0 . 2}$} & \multicolumn{3}{c}{ Temperatura $\pm \mathbf{1}^{\circ} \mathrm{C}$} \\
& 0.05 & 0.10 & 0.15 & 0.30 & 3.0 & 4.0 & 5.0 & 6.0 & 7.0 & 8.0 & 28 & 37 & 42 \\
\hline A & 4.0 & 4.9 & 4.5 & 5.0 & 5.0 & 4.7 & 5.0 & 5.0 & 4.8 & 4.2 & 5.0 & 4.2 & 3.8 \\
B & 1.5 & 1.2 & 1.7 & 2.6 & 3.7 & 3.3 & 3.2 & 3.6 & 4.2 & 1.4 & 4.8 & 4.0 & 2.6 \\
C & 4.1 & 3.7 & 4.0 & 4.6 & 4.8 & 5.0 & 4.8 & 4.6 & 4.6 & 2.9 & 4.8 & 4.5 & 1.7 \\
\hline
\end{tabular}




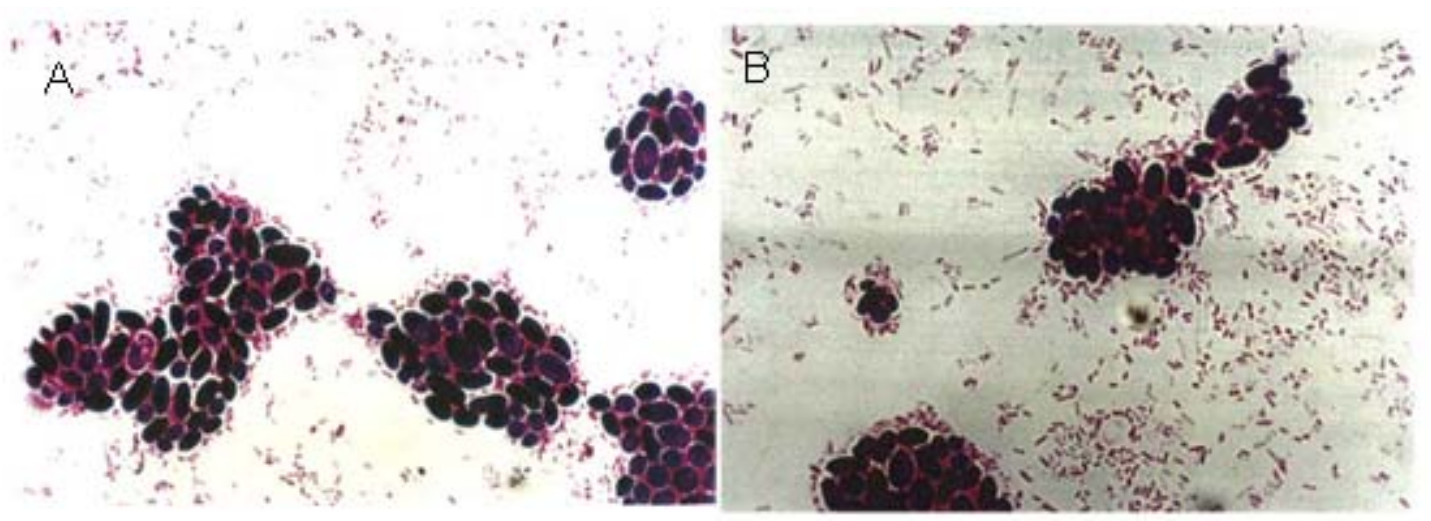

Figura 2. Microscopía óptica 100x, tinción de Gram. Prueba de adherencia entre E.coli y Saccharomyces: A (cepa A), B (cepa B).

estudio ( $A, B$ y C) frente a ninguno de los patógenos estudiados y tampoco entre las cepas A y C. Los sensidiscos de penicilina $(\mathrm{P} 100 \mu \mathrm{g})$ empleados como control mostraron halos de inhibición del crecimiento de $10 \mathrm{~mm}$ frente a los patógenos ensayados. La tabla 3 muestra los resultados de las cinéticas de crecimiento en erlenmeyers agitados de los 27 tratamientos realizados. Las $S_{0}$ experimentales presentaron desviaciones estándar entre 0.83 y 2.85 y coeficientes de variación entre 8 y $11 \%$. Para el cálculo de las $\mu_{\max }$ y las Ks se emplearon los datos experimentales. Los

Tabla 3. Datos promedio y parámetros cinéticos de los cultivos en erlenmeyer agitado.

\begin{tabular}{|c|c|c|c|c|c|c|c|}
\hline Tratamiento & $\begin{array}{c}\text { pH Final } \\
\pm 0.2\end{array}$ & $\begin{array}{l}\text { Glucosa } \\
\text { Exp. g/I }\end{array}$ & $\begin{array}{l}\mathbf{Y}_{(\mathrm{x} / 5)} \\
\mathbf{g} / \mathrm{g}\end{array}$ & $\mu_{(x)} h^{-1}$ & $\operatorname{td}(h)$ & $\mu_{(\max )} h^{-1}$ & $\mathrm{Ks}(\mathrm{g} / \mathrm{I})$ \\
\hline $\mathrm{T}_{1}$ & & 9.13 & 0.288 & 0.252 & 2.746 & & \\
\hline$T_{2}$ & 6.00 & 19.09 & 0.191 & 0.284 & 2.445 & 0.393 & 5.294 \\
\hline$T_{3}$ & 5.00 & 26.21 & 0.123 & 0.311 & 2.228 & & \\
\hline $\mathrm{T}_{4}$ & & 9.13 & 0.287 & 0.248 & 2.792 & & \\
\hline$T_{5}$ & 5.50 & 19.09 & 0.185 & 0.280 & 2.480 & 0.333 & 3.345 \\
\hline$T_{6}$ & 4.75 & 26.21 & 0.124 & 0.301 & 2.301 & & \\
\hline $\mathrm{T}_{7}$ & & 9.13 & 0.245 & 0.240 & 2.894 & & \\
\hline$T_{8}$ & 4.50 & 19.09 & 0.142 & 0.310 & 2.239 & 0.463 & 9.238 \\
\hline$T_{g}$ & & 26.21 & 0.125 & 0.320 & 2.169 & & \\
\hline $\mathrm{T}_{10}$ & 6.17 & 9.13 & 0.202 & 0.187 & 3.713 & & \\
\hline $\mathrm{T}_{11}$ & 5.00 & 19.09 & 0.182 & 0.248 & 2.796 & 0.370 & 8.208 \\
\hline$T_{12}$ & 5.17 & 26.21 & 0.115 & 0.273 & 2.538 & & \\
\hline$T_{13}$ & & 9.13 & 0.184 & 0.202 & 3.426 & & \\
\hline $\mathrm{T}_{14}$ & 5.50 & 19.09 & 0.195 & 0.266 & 2.604 & 0.582 & 23.400 \\
\hline $\mathrm{T}_{15}$ & 4.67 & 26.21 & 0.089 & 0.270 & 2.568 & & \\
\hline $\mathrm{T}_{16}$ & & 9.13 & 0.184 & 0.197 & 3.524 & & \\
\hline $\mathrm{T}_{17}$ & 4.50 & 19.09 & 0.157 & 0.320 & 2.165 & 0.518 & 13.68 \\
\hline $\mathrm{T}_{18}$ & 4.00 & 26.21 & 0.091 & 0.299 & 2.320 & & \\
\hline $\mathrm{T}_{19}$ & 6.33 & 9.13 & 0.272 & 0.215 & 3.230 & & \\
\hline $\mathrm{T}_{20}$ & 6.00 & 19.09 & 0.171 & 0.284 & 2.443 & 0.381 & 6.836 \\
\hline $\mathrm{T}_{21}$ & 5.17 & 26.21 & 0.136 & 0.291 & 2.386 & & \\
\hline $\mathrm{T}_{22}$ & & 9.13 & 0.265 & 0.216 & 3.205 & & \\
\hline$T_{23}$ & 5.50 & 19.09 & 0.157 & 0.263 & 2.636 & 0.368 & 5.157 \\
\hline$T_{24}$ & 4.67 & 26.21 & 0.131 & 0.284 & 2.438 & & \\
\hline $\mathrm{T}_{25}$ & & 9.13 & 0.259 & 0.215 & 3.219 & & \\
\hline$T_{26}$ & 4.50 & 19.09 & 0.151 & 0.253 & 2.745 & 0.386 & 6.165 \\
\hline $\mathrm{T}_{27}$ & 4.17 & 26.21 & 0.121 & 0.265 & 2.615 & & \\
\hline
\end{tabular}


tratamientos $T_{1}, T_{4}, T_{19}, T_{22} \quad y \quad T_{25}$ mostraron $Y_{(x / s)}$ ligeramente superiores, sin embargo las $\mu_{x}$ encontradas en los tratamientos $\mathrm{T}_{1}-\mathrm{T}_{3}, \mathrm{~T}_{5}, \mathrm{~T}_{6}, \mathrm{~T}_{8}, \mathrm{~T} 9, \mathrm{~T}_{12}, \mathrm{~T}_{14}$,

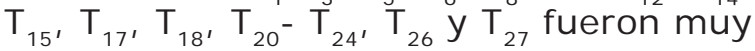
similares. El ANOVA entre las diferentes horas de la cinética y entre los tratamientos demostró diferencias significativas $(p \leq 0.05)$ y llevó al rechazo de Ho.

Para el cálculo de la $\mu_{\max }\left(\mathrm{h}^{-1}\right)$ y la $\mathrm{Ks}(\mathrm{g} / \mathrm{l})$ se agruparon los resultados de $\mathrm{S}_{0}(\mathrm{~g} / \mathrm{l})$ y $\mathrm{m}_{\mathrm{x}}$ $\left(h^{-1}\right)$ de los tratamientos en los cuales las variables independientes (cepa y $\mathrm{pH}$ inicial) coincidían (Tabla 3). De esta manera se encontraron $\mu_{\max }$ superiores para la cepa B a pH 5 y $6 \pm 0.2$; sin embargo, las cepas $A$ y $C$ pese a mostrar $\mu_{\max }\left(h^{-1}\right)$ muy similares tuvieron diferencias en cuanto a la afinidad por el sustrato (Ks); se encontró que a las condiciones de experimentación la cepa con mayor afinidad por el sustrato fue la cepa $A$ a pH $6 \pm 0.2\left(\mathrm{~T}_{4}-\mathrm{T}_{6}\right)$, con una $\mathrm{Ks}$ de $3.35 \mathrm{~g} /$ I. Se destaca que bajo las condiciones de experimentación la cepa B a pH 5 y $6 \pm 0.2$ presentó menor afinidad por el sustrato al tener valores de Ks altos.

El análisis de la interacción $X_{1}$ vs., $X_{3}$, fue altamente significativo y demostró que el nivel medio de $X_{1} y$ el nivel máximo $X_{3}$ generaron una superficie de respuesta superior bajo las condiciones del ensayo (Figura 3). De otro lado, se demostró que las variaciones en $\mathrm{X}_{2}$ no generaron superficies de respuesta a considerar en ninguno de los niveles (resultados no mostrados).

Teniendo en cuenta los resultados de las propiedades probióticas, la $\mu_{\max }\left(\mathrm{h}^{-1}\right)$ y la Ks $(g / l)$ encontrada en erlenmeyer agitado se seleccionó la cepa A para la producción experimental de biomasa en biorreactor. La

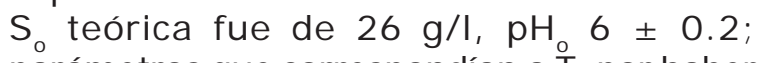
parámetros que correspondían a ${ }^{\circ}{ }_{6}$ por haber presentado mayor afinidad por el sustrato. La $\mu_{\mathrm{x}}\left(\mathrm{h}^{-1}\right)$ y el $\mathrm{Y}_{(\mathrm{x} / \mathrm{s})}(\mathrm{g} / \mathrm{g})$ obtenidos en biorreactor fueron ligeramente superiores a los encontrados en erlenmeyer agitado, pese a que $\mathrm{S}_{\text {o }}$ experimental fue $\sim 24 \mathrm{~g} / \mathrm{l}$; dos gramos menos que la concentración experimentada en $\mathrm{T}_{6}$. La cinética de crecimiento y el consumo de sustrato se muestra en la figura 4.
$L N(X X 0)=-2032,069+40,0398^{*} x+0,0476^{*} y-0,197^{*} x^{*} x+0,0005^{*} x^{*} y-0,0024^{*} y^{*} y$

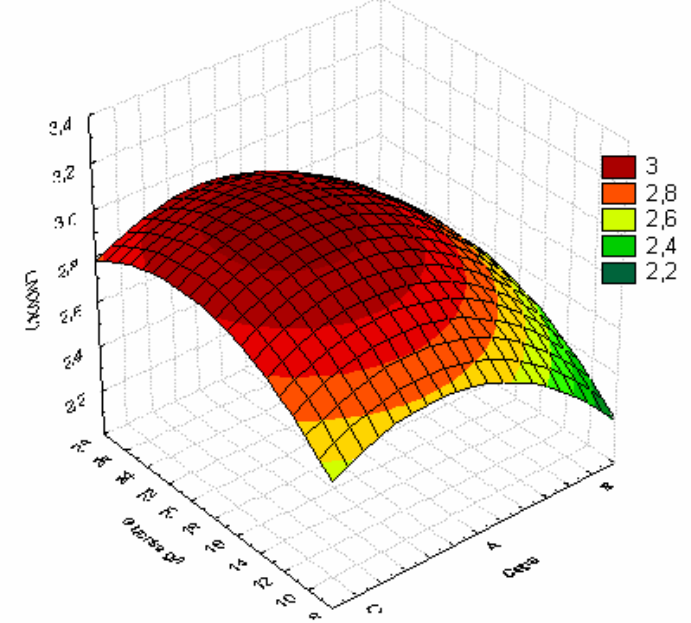

Figura 3. Superficie de respuesta medida como Biomasa $(\mathrm{g} / \mathrm{l})$ transformada a $\operatorname{Ln}\left(\mathrm{X} / \mathrm{X}_{0}\right)$. Muestran los dos factores (cepas, concentración de glucosa) de mayor influencia en sus tres niveles sobre la superficie de respuesta.

La biomasa de la cepa A obtenida en biorreactor fue empleada para las pruebas de secado a dos temperaturas diferentes. Los valores de viabilidad, la pureza, los gramos de biomasa seca obtenidos y el porcentaje de $\mathrm{N}_{2} / \mathrm{g}$ de biomasa seca se observan en la tabla 4. La recuperación de biomasa seca fue 1.5 veces mayor a $42 \pm 1^{\circ} \mathrm{C}$, aunque se perdió algo de viabilidad $y$ el $\%$ de $\mathrm{N}_{2} / \mathrm{g}$ de biomasa seca fue muy similar después del empleo de ambas temperaturas (Tabla 4).

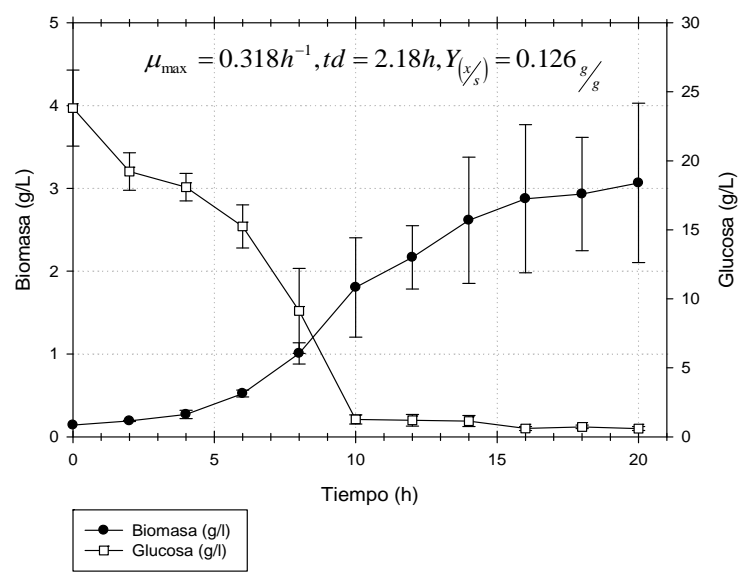

Figura 4. Curva de crecimiento de la cepa $A$ en medio YPD ( $\mathrm{S}_{0}$ experimental $\sim 24 \mathrm{~g} / \mathrm{l}$ de glucosa), $\mathrm{pH}_{0} 6 \pm 0.2,30 \pm 1^{\circ} \mathrm{C}, 250$ r.p.m., $y$ 2 v.v.m. 
Tabla 4. Resultados del ensayo preliminar de secado de biomasa (Cepa A)

\begin{tabular}{|c|c|c|c|c|c|c|c|}
\hline \multirow{2}{*}{$\begin{array}{l}\text { Temp. de } \\
\text { secado } \\
\left({ }^{\circ} \mathrm{C}\right)\end{array}$} & \multirow{2}{*}{$\begin{array}{l}\text { Tiempo de } \\
\text { secado (h) }\end{array}$} & \multicolumn{2}{|c|}{ Viabilidad UFC/ml } & \multirow{2}{*}{$\begin{array}{c}\text { Prueba } \\
\text { de } \\
\text { Pureza }\end{array}$} & \multirow{2}{*}{$\begin{array}{l}\text { Biomasa } \\
\text { seca }(g / I)\end{array}$} & \multicolumn{2}{|c|}{$\% \mathrm{~N}_{2} / \mathrm{g}$ de Biomasa seca } \\
\hline & & $\begin{array}{c}\text { Antes de } \\
\text { secar }\end{array}$ & $\begin{array}{c}\text { Después de } \\
\text { secar }\end{array}$ & & & $\begin{array}{c}\text { Antes de } \\
\text { secar }\end{array}$ & $\begin{array}{c}\begin{array}{c}\text { Después de } \\
\text { secar }\end{array} \\
\end{array}$ \\
\hline 37 & 48 & $4.30 E+13$ & $9.20 E+08$ & $100 \%$ & 1.47 & \multirow{2}{*}{8.37} & 6.32 \\
\hline 42 & 34 & $3.10 \mathrm{E}+11$ & $6.10 E+08$ & $100 \%$ & 2.25 & & 6.9 \\
\hline
\end{tabular}

\section{DISCUSIÓN}

En general las levaduras han sido poco utilizadas como probióticos, principalmente se han utilizado microorganismos del género Lactobacillus spp., sin embargo, existen algunos estudios con S. cerevisiae var boulardii que han mostrado el papel de estas en procesos de inhibición de la colonización de bacterias enteropatógenas (3). El mecanismo de acción, aunque todavía no ha sido bien definido, está relacionado con las características bioquímicas, fisiológicas y de crecimiento (14).

S. cerevisiae ha sido reportada como suplemento en la dieta de animales monogástricos (15), en los que su acción probiótica reduce la presencia de enteropatógenos, produce cambios favorables en la mucosa intestinal y mejora el comportamiento productivo (16). También se le ha reconocido la capacidad de promover el crecimiento, aumentar la producción de vitamina $B$, ayudar a la ganancia de peso, mejorar la digestión de algunos alimentos, estimular el sistema inmune, mejorar la asimilación de nutrientes y corregir el balance de la población microbiana.

Las pruebas de tolerancia a sales biliares, $\mathrm{pH}$ y temperaturas simularon los rangos existentes en el tracto gastrointestinal, mediante un método in vitro que permite evaluar a nivel semicuantitativo la tolerancia de la levadura. Los resultados obtenidos muestran que en las 3 cepas se obtuvieron ICA $\geq 4.0$, en las condiciones evaluadas. Según Ortiz et al (17) S. cerevisiae posee proteínas integrales de membrana unidas a ATP (proteínas $A B C$ ), responsables de la translocación de las sales biliares y pueden transportar eficientemente ácidos biliares conjugados. Otro mecanismo por el cual la levadura es resistente a altas concentraciones de sales biliares, se centra en la acumulación de polioles y glicerol, como mecanismo para regular la presión osmótica de la célula. Moser y Savage (18), indicaron que las especies de levaduras que toleran sales biliares contribuyen a la función de los microorganismos en el tracto gastrointestinal (19); lo cual deberá ser demostrado posteriormente con nuestras sepas.

En relación a la tolerancia a pH los resultados obtenidos son comparables con los reportes de Membre et al (20), quienes evaluaron rangos de $\mathrm{pH}$ encontrando que el $\mathrm{pH}$ óptimo está entre 3.5 y $5.0 \pm 0.2$ y que a $2.5 \pm 0.2$ se observa una disminución del $30 \%$ en la tasa de crecimiento de S. cerevisiae (6). La tolerancia a pH puede deberse a dos tipos de anti-transportadores de $\mathrm{Na}^{+} / \mathrm{H}^{+}$que posee la levadura; Nhalp, encontrado en la membrana plasmática y el otro es $\mathrm{Nhxlp}$, que se localiza en el compartimiento endosomal prevacuolar (20). Estas proteínas catalizan el intercambio de cationes monovalentes $\left(\mathrm{Na}^{+} \circ \mathrm{K}^{+}\right)$e $\mathrm{H}^{+}$a través de las membranas, de tal modo que regulan las concentraciones de cationes y $\mathrm{pH}$ a nivel citoplasmático y de organelos $(21,22)$. Otro de los posibles mecanismos de regulación es a través de la ATPasa localizada en la membrana citoplasmática. Esta puede crear un gradiente electroquímico de protones que conduce al transporte secundario de solutos y que está implicado en el mantenimiento del $\mathrm{pH}$ cercano a la neutralidad $(23,24)$.

De acuerdo con las pruebas realizadas a las cepas nativas de S. cerevisiae, se puede observar que cumplen con los requisitos establecidos por Fuller (25) para ser consideradas como posibles probióticos. Estos requisitos son capacidad de sobrevivir en diferentes rangos de $\mathrm{pH}$, resistir 
concentraciones de sales biliares y no disminuir la tasa de crecimiento celular a 37 으 para ejecutar acciones favorables como probióticos en el hospedero $(3,14)$. El hecho de que la cepa A tenga un ICA $\geq$ 4.0 a estas condiciones es favorable desde la perspectiva de su posible utilización como probiótico. Según Domitille et al (26), en las bacterias ácido-lácticas (BAL), el mecanismo por el cual se presenta mayor actividad antibacteriana está relacionado con el pH bajo en el medio, debido a la producción de ácidos orgánicos que pueden actuar como bacteriocinas.

Uno de los criterios importantes para evaluar la capacidad probiótica de una cepa es la habilidad para adherirse a la superficie de la mucosa del tracto gastrointestinal ya que la formación de aglomerados en el epitelio, contribuye con la exclusión competitiva de los patógenos, previniendo la colonización de estos (14). S. cerevisiae, para adherirse a las células epiteliales del intestino emplea manoproteínas de la membrana celular (adhesinas) (27). Las adhesinas tipo lectina o sensible a azúcares se unen a un residuo glicoconjugado específico de superficie de las células epiteliales del intestino (28). Esta adherencia puede darse por unión a manosa (adhesina Flol) ó por unión a manosa, glucosa o maltosa (adhesina nuevo Flo) (29). Una vez adherida ejercen parte de su efecto probiótico impidiendo la adherencia de las bacterias patógenas al competir con estas por sustrato y sitios de adherencia.

La prueba preliminar de inhibición de la adherencia de los patógenos evaluó cualitativamente la formación de agregados de S. cerevisiae, y la disposición de los patógenos en torno a dichos agregados. Este ensayo evidenció que después de 24 horas de incubación a $37^{\circ} \mathrm{C}$ las células de levadura forman agregados que evitarían in vivo la adherencia de los patógenos al epitelio gastrointestinal.

La evaluación mostró que los patógenos empleados en el estudio tienen mayor afinidad por las cepas $\mathrm{A}$ y $\mathrm{C}$ respecto a la cepa B (control). De la misma manera la cepa A propició mayor adherencia de Salmonella spp., y E.coli y en menor proporción de
Shigella spp. Esta es una característica importante ya que las principales patologías en aves de corral son las causadas por S.gallinarum-pullorum, S. typhimurium, S. heidelberg y S. enteritidis (30). En contraste, la cepa control (B) evidenció menor capacidad para propiciar la adherencia excepto frente a Shigella spp., (patógeno importante en humanos).

Aunque los mecanismos de acción de las levaduras utilizadas como probióticos son amplios, se reconoce que su acción no solamente se debe a la exclusión competitiva disminuyendo la adherencia del patógeno al epitelio gastrointestinal o la capacidad de adherirse a las microvellosidades intestinales, sino también al antagonismo. De esta manera las pruebas de adherencia y antagonismo se relacionan entre si ya que ambas ejercen la acción antimicrobiana. Es difícil evaluar in vitro el antagonismo ya que propiciar las condiciones gastrointestinales es imposible.

La prueba de antagonismo frente a patógenos demostró que ninguna de las cepas de levaduras produce sustancias antimicrobianas que puedan difundirse al medio y sean capaces de contrarestar in vitro el crecimiento de los patógenos evaluados, lo que confirma que el mecanismo de acción de las levaduras es diferente al de bacterias como Lactobacillus spp., o Bifidobacterium spp., que producen bacterioriocinas y ácido láctico (26). A diferencia, las levaduras compiten por los sitios de adherencia y por la exclusión competitiva; lo que hace pensar que estas son más resistentes al ambiente gastrointestinal siendo su colonización y multiplicación más fructífera en comparación con los patógenos.

La selección de la cepa A para el estudio en biorreactor se realizó pese a que las $\mu_{\max }$ entre las cepas A y $C$ son similares, pero la afinidad por el sustrato marcó la diferencia entre estas, lo que permitió ubicarlas en orden descenderte de afinidad $\mathrm{A}>\mathrm{C}>\mathrm{B}$. De otro lado, aunque no se muestran los resultados, es destacable que el $\mathrm{pH}$ a las condiciones de experimentación no jugó un papel importante en la producción de biomasa. En el análisis de superficies de 
interacción la variable dependiente $\mathrm{LN}\left(\mathrm{X} / \mathrm{X}_{0}\right)$ presentó variaciones significativas únicamente como consecuencia de la interacción de los factores cepa y $\mathrm{S}_{0}$; resultados que permitieron la selección de $\mathrm{T}_{4}-\mathrm{T}_{6}$ para el cultivo en biorreactor. Sin embargo, se pudieron establecer las condiciones adecuadas para cada cepa. De otro lado, la ecuación que se obtuvo al caracterizar la superficie obtenida sugiere un proceso de optimización en el cual deben participar $X_{1}$ (nivel medio), $X_{2}$ (en forma variable) y $x_{3}$ debe encaminarse a la búsqueda de niveles superiores, evitando la represión por sustrato.

El propósito del cambio de geometría es examinar el comportamiento de las células; los cambios en la capacidad de los equipos son de menor importancia en comparación con la pérdida o variación del rendimiento que suele producirse. Incluso aunque la geometría del reactor, el método de aireación el diseño del rodete y otras características sean similares en pequeña y gran escala el efecto sobre la actividad de las células puede ser importante (31). La geometría empleada (reactor de 2l), el suministro de 2 v.v.m., y las condiciones de cultivo extrapoladas desde los ensayos en erlenmeyers agitados; hizo evidente que los cambios en la agitación y la inyección de aire propiciaron: i mejora en la superficie de contacto medio: $\mathrm{O}_{2}$, ii mejor homogeneidad del medio, iii disminución del efecto vortex y iv el aumento en el coeficiente volumétrico de transferencia de oxígeno $\left(K_{L} a\right)(31)$ y pese a que el $S_{0}$ experimental estuvo $\sim 2 \mathrm{~g}$ por debajo de la concentración empleada en $\mathrm{T}_{4}-\mathrm{T}_{6}$, se encontró una $\mu_{x}$ muy similar a la $\mu_{\max }$ detectada con diferentes $S_{0}$ y $Y_{(x / s)}$ también similar a $\mathrm{T}_{4}-\mathrm{T}_{6}$ (Tabla 3).

En la actualidad en el país aún no existe una norma encaminada a la formulación de dietas suplementadas con probióticos para monogástricos. En sentido general cuando se detecta que un microorganismo tiene capacidad probiotica in vitro, es importante evaluar la viabilidad y resistencia durante el procesamiento al que serán sometidos para su posible comercialización. Uno de los primeros pasos para la producción de probióticos es el cultivo, en el cual se debe obtener una alta concentración de los microorganismos a emplear y posteriormente realizar el lavado y secado de los mismos.

En el presente estudio se evaluó el contenido de $\mathrm{N}_{2}$ de la biomasa obtenida por fermentación discontinua en caldo YPG. Las concentraciones obtenidas fueron inferiores con respecto a la Norma Técnica Colombiana (NTC 1807) en la cual se establece que la levadura tanto húmeda como seca para consumo debe tener $\sim 40 \%$ mínimo de proteína total (13). Sin embargo, es importante destacar que las células permanecieron viables y puras a lo largo del proceso, tanto a $37^{\circ} \mathrm{C}$ como a $42^{\circ} \mathrm{C}$ manteniéndose en la escala logarítmica de $10^{7}$, siendo este un aspecto favorable en la futura formulación de un biopreparado. Es de destacar que la norma que regula la concentración de proteínas en el biopreparado es para productos de consumo humano.

En este trabajo se logró identificar hasta propiedades probióticas como la tolerancia a $\mathrm{pH} 3 \pm 0.2,0.3 \%(\mathrm{p} / \mathrm{v})$ de sales biliares, $42^{\circ} \mathrm{C}$ de temperatura, así como la adherencia a las levaduras de patógenos tales como Salmonella spp., E.coli y Shigella spp, pese a que estos resultados no son evidencia de exclusión competitiva en general los resultados obtenidos ofrecen pautas para optimizar el proceso biotecnológico con el objetivo de mejorar la concentración de proteínas totales en la producción del principio activo para un biopreparado, con posible aplicación probiótica en monogástricos. Entendiendo que los mecanismos de acción de los microorganismos con efectos probióticos varían entre bacterias y levaduras se ha planteado el estudio de adherencia de las levaduras a células de organismos superiores (Caco-2) para simular la fijación a las microvellosidades del tracto gastrointestinal. 


\section{REFERENCIAS}

1 Wolf K. Nonconventional Yeast in Biotechnology. A Handbook. 1996; Berlin: Springer Verlag. 618p.

2 Lee $Y$, Lim C, Teng W, Ouwehand A, Tuomola E, Salminen S. Quantitative Approach in the Study of Adhesion of Lactic Acid Bacteria to Intestinal Cells and Their Competition with Enterobacteria. Appl Env Microbiol 2000; 66(9): 3692-3697.

3 Hamilton M. Probiotic Remedies Are Not What They Seem. British Medical Journal 1996; 312: 55-56.

4 Oyetayo VO, Oyetayo FL. Potencial of Probiotics as Biotherapeutic Agents Targeting the I nnate I mmune System. Afr J Biotechnol 2005; 4(2): 123-127.

5 Rivas J, Bastidas P, Díaz T, Hahn M, Moya A. Efecto de la suplementación con Saccharomyces cerevisiae sobre el comportamiento reproductivo en rebaños lecheros de la zona alta del estado Mérida. Zoot Trop 2006; 24(3): 379-391.

6 Meza RA, Monroy AF, Mercado M, Poutou RA, Rodríguez P, Pedroza AM. Study of the Stability in Real Time of Cryopreserved Strain Banks. Univ Scient 2004; 9(2): 35-42.

7 Maldonado CM, Bayona MA, Poutou RA. Efecto Antagónico de Zymomonas mobilis spp. Frente a Salmonella sp. y Proteus mirabilis. Univ Scient 2001; 6(2): 17-25.

8 Mossel DAA, Moreno B, Struijk CB. Microbiología de los alimentos, Fundamentos ecológicos para garantizar y comprobar la integridad (inocuidad y calidad) microbiológica de los alimentos. 2 ed. 2003; Zaragoza: Acribia S.A. 703p.

9 Hernández R, Ospina SP. Capacidad probiótica de cepas nativas de Saccharomyces spp. Frente a
Clostridium perfringens y Clostridium septicum. Bogotá, D.C, Colombia: Departamento de Microbiología, Pontificia Universidad J averiana; 2000.

10 Miller G. Use of Dinitrosalicilic Acid Reagent for Determination of Reducing Sugar. Anal Chem 1959; 31(3): 426428.

11 Burquillo FJ, Holgado M, Bardsley WG. Uso del paquete estadístico SIMFIT en la enseñanza del análisis de datos en ciencias experimentales. J Sci Edu 2003; 4(1): 8-14.

12 Jiménez $A$, Vanegas D. Efecto antagónico de levaduras nativas frente a Salmonella enteritidis y $\mathrm{E}$. coli. Bogotá, D.C., Colombia: Departamento de Microbiología, Pontificia Universidad Javeriana; 1999.

13 NTC. Industria alimentaria. Levadura para panificación. Bogotá, D.C, Colombia: Norma Técnica Colombiana 1807; 1982.

14 Fuller RA. Probiotics in man and animals. J Appl Bacteriol 1989; 66: 364-378.

15 Agarwal N, Kamra D, Chaudhary L, Sahoo A, Pathak N. Selection of Saccharomyces cerevisiae strains for use as a microbial feed additive. Let Appl Microbiol 2000; 31: 270-273.

16 Kumprevhtová D, Zobac P, Kumprecht I. The effect of Saccharomyces cerevisiae SC47 on chicken broiler performance and nitrogen output. Czech J Anim Sci 2000; 45: 169-177.

17 Ortiz D, St.Pierre M, Abdulmessih A, Arias I. A yeast ATP-binding cassettetype protein medianting ATP-dependent bile acid transport. J Biol Chem 1997; 272: 15358-15365.

18 Moser SA, Savage DC. Bile Salt Hydrolase Activity And Resistance To Toxicity Of Conjugated Bile Salts Are 
Unrelated Properties In Lactobacilli. Appl Env Microbiol 2001; 67(8): 34763480.

19 Duncan S, Scott K, Ramsay A, Harmsen H, Gjalt W, Colin S, et al. Effects of Alternative Dietary Substrates on Competition between Human Colonic Bacteria in an Anaerobic Fermentor System. Appl Env Microbiol 2003; 69: 1136-1142.

20 Membré J M, Kubaczka M, Chene C. Combined Effects of $\mathrm{pH}$ and Sugar on Growth Rate of Zygosaccharomyces rouxii, a Bakery Product Spoilage Yeast. Appl Env Microbiol 1999; 69(2): 11361142.

21 Mitsui K, Yasui $\mathrm{H}$, Nakamura $\mathrm{N}$, Kanazawa $\mathrm{H}$. Oligomerization of the Saccharomyces cerevisiae $\mathrm{Na}+/ \mathrm{H}+$ antiporter Nhalp: Implications for its antiporter activity. Biochim Biophys Acta 2005; 1720: 125-136.

22 Ohgaki R, Nakamura N, Mitsui K, Kanazawa $\mathrm{H}$. Characterization of the ion transport activity of the budding yeast $\mathrm{Na}+/ \mathrm{H}+$ antiporter, Nhalp, using isolated secretory vesicles. Biochim Biophys Acta 2005; 1712: 185-196.

23 Viegas C, Almeida P, Cavaco M, I. C. The HI-ATPase in the plasma membrane of Saccharomyces cerevisiae is activated during growth latency in Octanoic Acid-supplemented medium accompanying the decrease in intracellular $\mathrm{pH}$ and cell viability. Appl Env Microbiol 1998; 64: 779-783.
24 Sychrovae H, Ramirez J, Peña A. Involvement of Nhal antiporter in regulation of intracellular $\mathrm{pH}$ in Saccharomyces cerevisiae. Microbiol Let 1999; 171: 167-172.

25 Fuller RA. Probiotics. The scientific basis. 1992; Cambridge, Great Britain: Chapman and Hall. 398p.

26 Domitille $\mathrm{F}, \mathrm{Ce}^{\prime}$ dric $\mathrm{N}$, Berger $\mathrm{M}$, Coconnier V, Moal L, Servin A. pH-, Lactic Acid-, and Non-Lactic AcidDependent Activities of Probiotic Lactobacilli against Salmonella enterica serovar typhimurium. Appl Env Microbiol 2005; 71(10): 6008-6013.

27 Tuitte M. Saccharomyces. Biotechnology Handbooks. Vol. 4. 1991; New York, USA: Plenum Press. 10-23p.

28 Giannasca K, Giannasca P, Neutra M. Adherence of Salmonella typhimurium to Caco-2 Cells: Identification of a Glycoconjugate Receptor. I nfect I mmu 1996; 16: 135-145.

29 Verstrepen K, Klis F. Flocculation, adhesion and biofilm formation in yeasts. Mol Microbiol 2006; 60: 5-15.

30 Chambers JR, Lu X. Probiotics and Maternal Vaccination for Salmonella Control in Broiler Chickens. J Appl Poult Res 2002; 11: 320-327.

31 Doran PM. Principios de ingeniería de los bioprocesos. 1998; Zaragoza, España: Acribia S. A. 468p. 